\title{
Discrete carcinomatous metastases in the extraocular muscles
}

\author{
NORMAN ASHTON AND GWYN MORGAN \\ Department of Pathology, Institute of Ophthalmology, University of London
}

The orbit is a rare site for metastatic carcinoma (Duke-Elder, 1952) and, although such orbital deposits may commonly involve muscle secondarily, discrete metastatic tumours in the extraocular muscles are extremely rare, as in muscle generally (Willis, 1952, 1953). A search of the literature has revealed four previous cases: two from carcinoma of the breast (Wintersteiner, I899; Bedford and Daniel, 1960), one from carcinoma of the lung (Horner, r 864), and one from malignant melanoma of the skin (Adelstein and Schmidt, 1968). This paper reports two further cases of extraocular muscle metastases from primary carcinoma of the breast, and outlines some of the diagnostic difficulties which arose.

\section{Case reports}

Case r, a housewife aged 58 years, presented with a lump of 2 months' duration in the left upper lid towards the inner canthus. Apart from a sense of heaviness of the lid there was no pain or any other symptom. A biopsy was taken, but the histology proved puzzling; the biopsy was repeated and a malignant neoplasm of unknown origin was reported. A third biopsy was diagnosed by the hospital pathologists as fibrosarcoma.

\section{Surgery}

Exploration of the orbit revealed a tumour mass discretely involving the extraocular muscles, and it was widely excised.

\section{Histopathology (5957/59)}

Sections of all biopsies stained with haematoxylin and eosin showed identical histological features. The orbital muscle was infiltrated by an entirely anaplastic mass of polyhedral, spheroidal, and spindle cells having hyperchromatic nuclei with abundant pinkish cytoplasm and a tendency to arrange themselves in whorls or columns: mitotic figures were not seen (Figs 1, 2, and 3).

An interesting feature of this case was the great difficulty in reaching a conclusive diagnosis; there were several suggestions, most of which, when looked at in retrospect, were surprisingly wide of the mark. The lesion was at first thought to be a xanthomatous deposit, but fat stains of frozen sections were negative and at this early stage a malignant synovioma or secondary deposit were also queried. Sections were sent to a number of senior pathologists for second opinions and the replies received included meningioma, atypical fibrosarcoma, and renal carcinomatous metastasis, while a Consultant Histological Panel suggested myoblastoma, meibomian gland tumour, or meningioma.

\section{Subsequent clinical course}

Investigation in hospital failed to reveal a primary tumour. The orbital neoplasm was widely excised and the patient was discharged from hospital. One year after the onset of the lump in the 


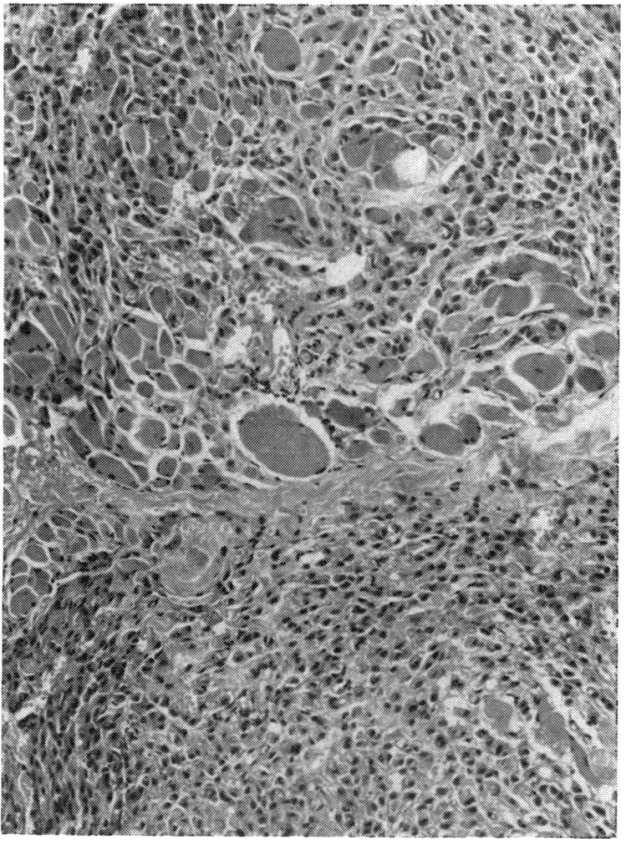

FI G. I Case I. Anaplastic infiltration of the extraocular muscle by neoplastic cells. Haematoxylin and eosin. $\times 100$

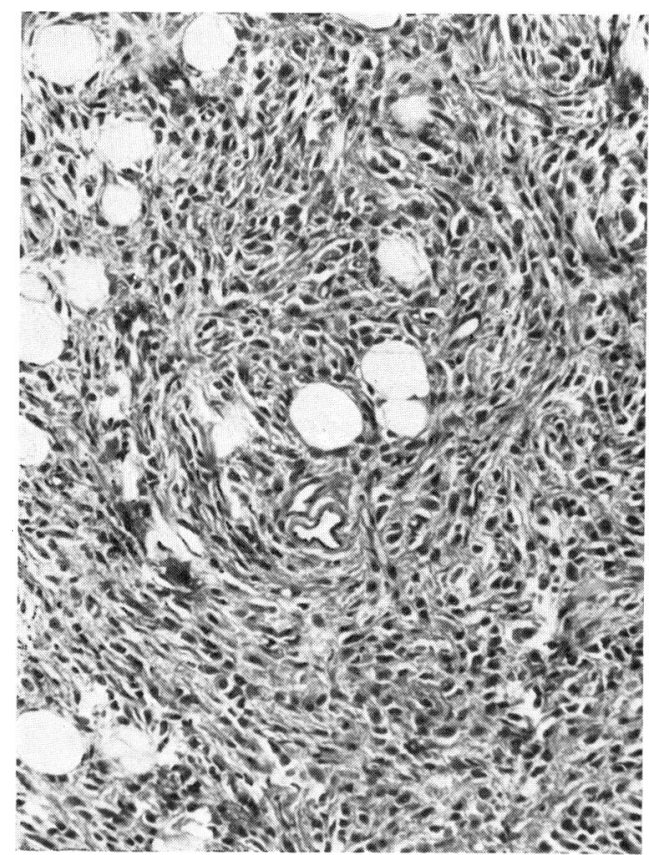

FIG. 2 Case I. Another area, showing spindle and polyhedral cells in whorl formation.

Haematoxylin and eosin. $\times 160$

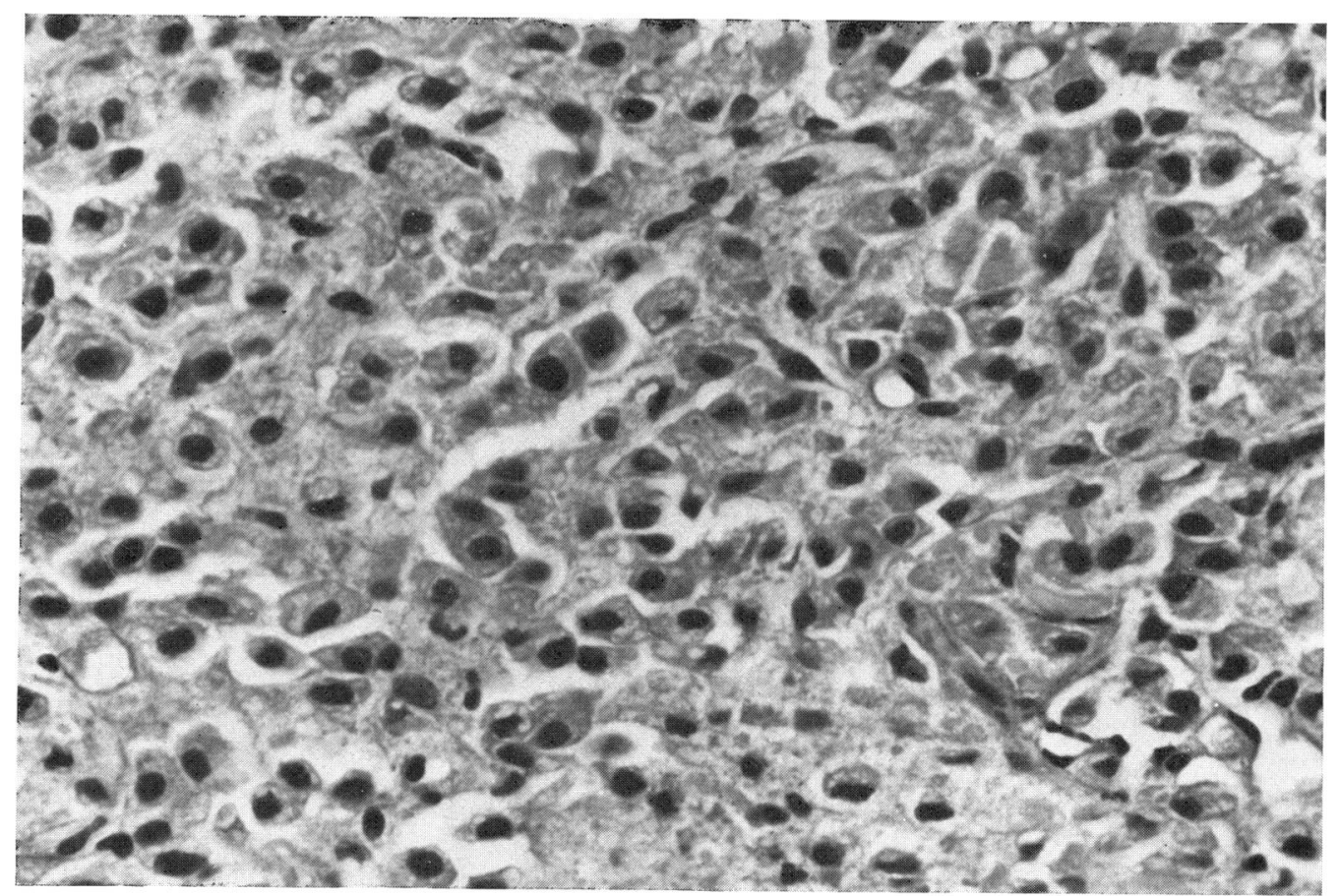

FIG. 3 Case I. High-power view, showing polyhedral and spheroidal cells with hyperchromatic nuclei and abundant eosinophilic cytoplasm. Haematoxylin and eosin. $\quad \times 450$ 
lid the patient was readmitted to hospital with lower back pain of I month's duration. Radiological studies showed metastatic deposits in the lumbar spine. In addition, general examination revealed in the right breast a small, freely mobile lump, which the patient said had been present for 20 years and had shown a very slight increase during that period. Enlarged right supraclavicular lymph nodes were present and there was a small skin nodule in the epigastric region. Sections of the breast tumour (Fig. 4) and a lymph node (Fig. 5) showed infiltration by an anaplastic spheroidal cell carcinoma, but there were no spindle cells or whorl formation and the cells lacked the nuclear hyperchromatism and the abundant eosinophilic cytoplasm of the orbital tumour. A diagnosis was made of carcinomatosis with a primary tumour in the breast.

Hypophysectomy was performed resulting in a temporary alleviation in the back pain and a decrease in size of the lymph nodes.

The patient developed a leuco-erythroblastic anaemia and died $2 \frac{1}{2}$ years after the onset of the orbital lesion. A post mortem examination was not made.

Case 2, a housewife aged 49 years, presented with right ptosis and a firm superior orbital swelling of recent onset. Curiously this mass practically disappeared after penicillin therapy for a coincidental phlebitis, but it enlarged again some months later involving both upper and lower lids, and a biopsy was performed.

\section{Histopathology (1802/58)}

Sections of the orbital biopsy showed a small fibrous nodule containing strands of voluntary muscle, and the whole tissue was diffusely infiltrated with round, polyhedral, and star-shaped cells showing ample eosinophilic cytoplasm (Figs 6 and 7, overleaf). It was considered undoubtedly to be a malignant growth, but its completely anaplastic nature gave no indication as to its origin or whether it was primary or secondary in the orbit. No further communication was received about this case.

Fifteen years afterwards, however, we came across an article by Bedford and Daniel (1960) which had described a case of discrete carcinomatous metastases in the extraocular muscles from a primary in the breast. The histological features they illustrated were identical with those in our two cases.

A follow-up enquiry with reference to our second case was, therefore, made and the information received was that the patient had died $6 \frac{1}{2}$ years later of carcinomatosis due to carcinoma of the breast. At this time we were also informed that she had had a tumour of the breast for some years before consulting a doctor, and there now seemed to be little doubt that the orbital tumour was in fact a secondary deposit from this site.

\section{Discussion}

As previously stated, carcinomatous metastases of the extraocular muscles are extremely rare, and these two cases make a total of six cases that have been reported, and represent the third and fourth cases in which the primary tumour was in the breast. The reason why secondary tumours are rarely seen in voluntary muscle is unknown and one can only speculate as to the cause. It may possibly be due to the fact that the muscles are in a more or less constant state of movement, thus preventing the lodgement of neoplastic cells or producing an unsuitable chemical environment for their continued growth.

The most interesting point, however, is the completely undifferentiated and unusual appearances of the tumours within the muscle, as shown in both our cases and that of Bedford and Daniel (1960); we suggest that, when such histological features are seen in the future, they should direct attention to the possibility of a primary carcinoma of the breast, which, in any case, is the commonest primary site of carcinomatous metastases in the orbit (Reese, 1963). 


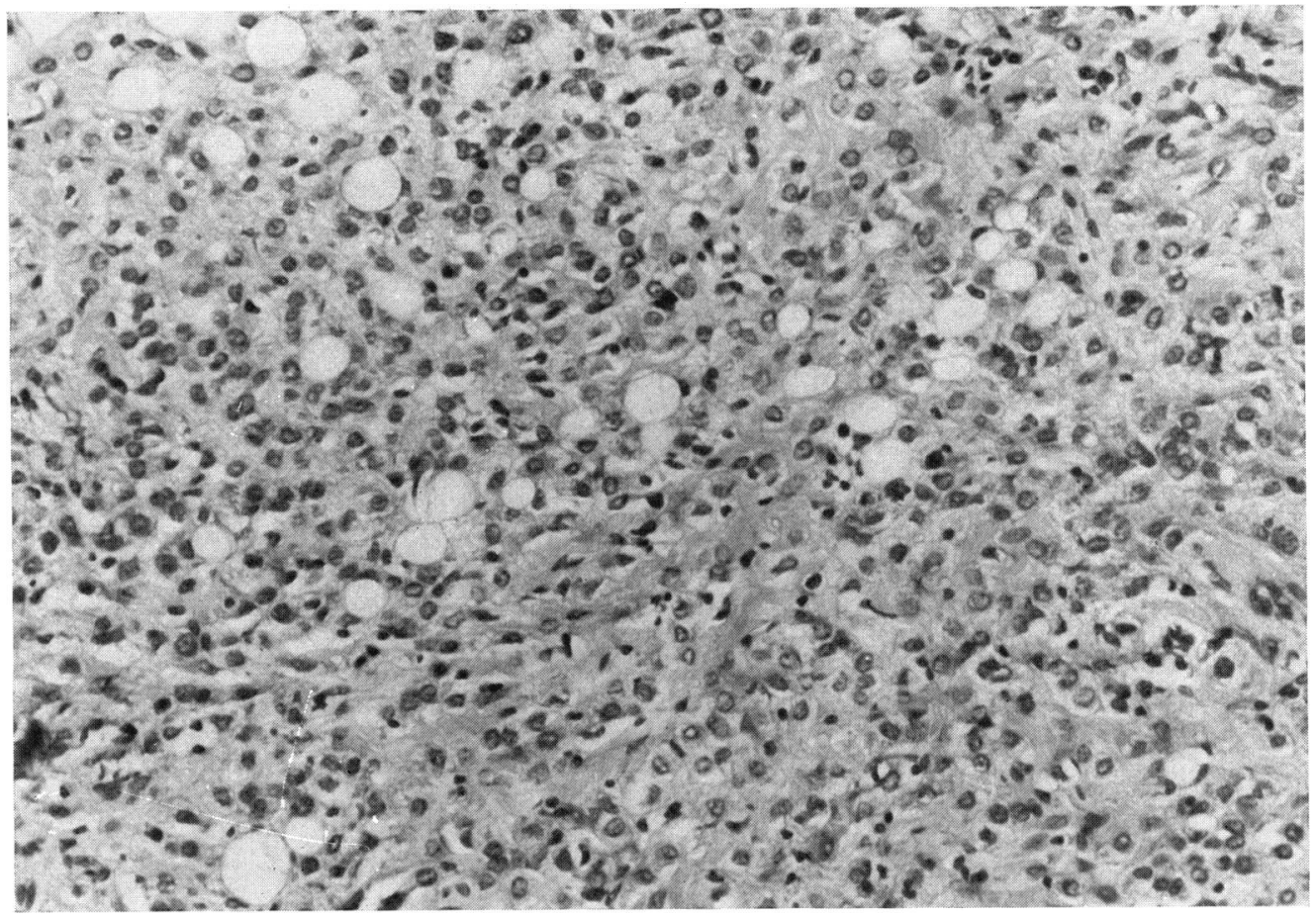

FIG. 4 Case I. Spheroidal-cell carcinoma of breast. Note that this primary growth is also anaplastic but differs somewhat from the histology of the orbital metastasis. Haematoxylin and eosin. $\times 180$

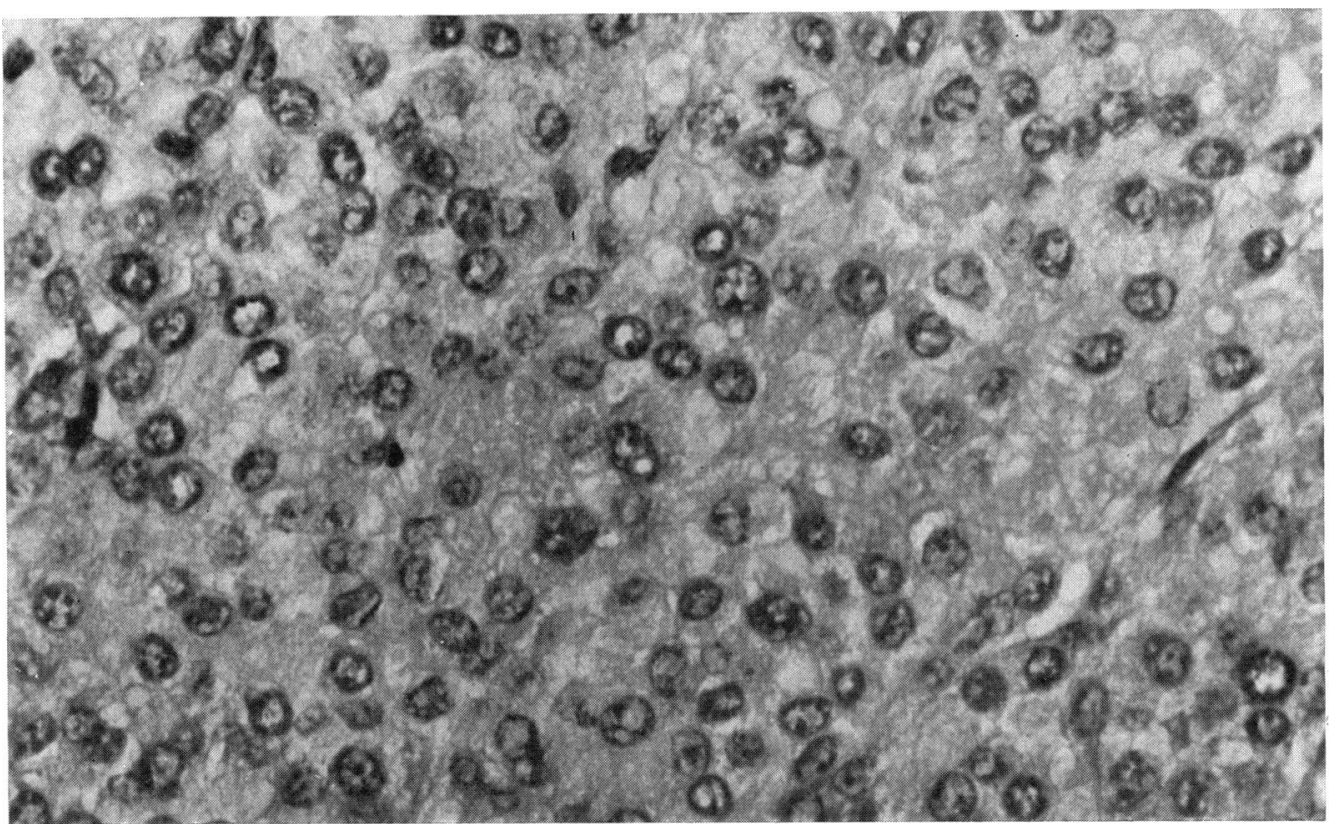

FIG. 5 Case I. Carcinomatous metastasis in a supraclavicular lymph node. Note that the growth is entirely spheroidal-cell in type and differs from the orbital metastasis (cf. Figs 1, 2, and 3). Haematoxylin and eosin. $\times 720$ 


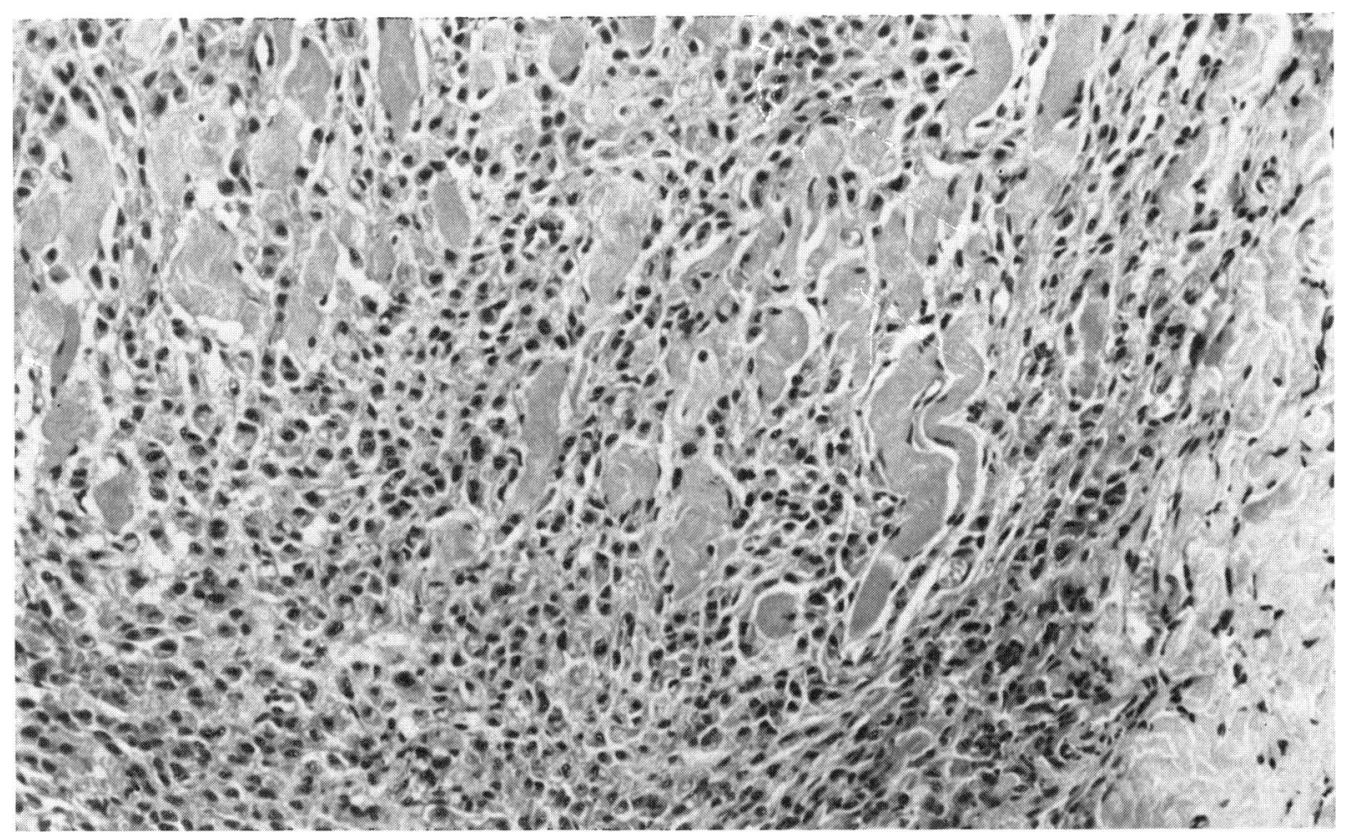

FIG. 6 Case 2. Extraocular muscle infiltrated by spheroidal and polyhedral cells. Haematoxylin and eosin. $\times 180$

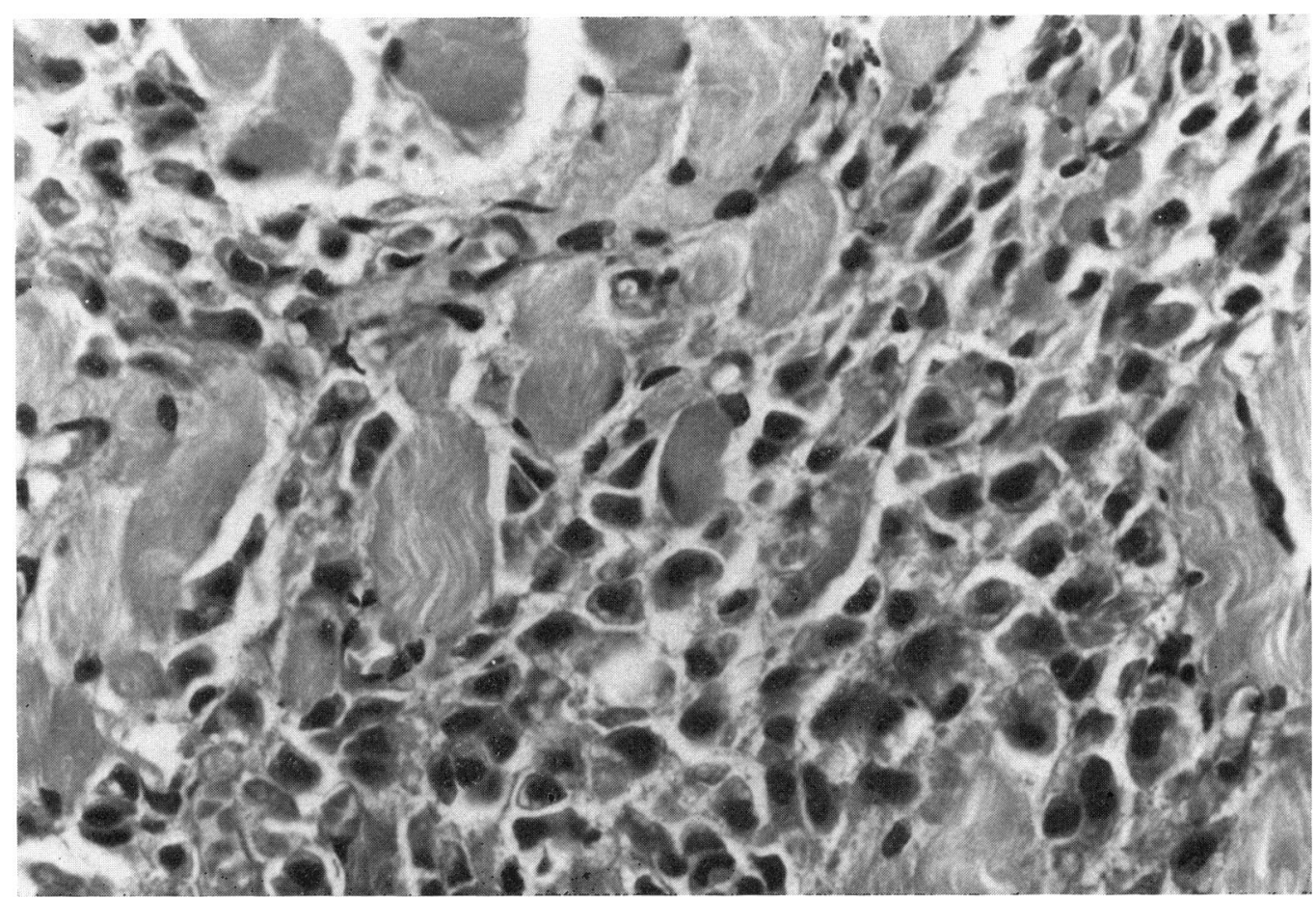

FIG. 7 Case 2. High-power view of Fig. 6, showing neoplastic cells with hyperchromatic nuclei and abundant cytoplasm. Note the striking similarity to Case I (cf. Fig. 3). Haematoxylin and eosin. $\quad \times 720$ 
We are grateful to Mr. G. E. Knight for technical assistance and to Miss E. FitzGerald for secretarial help.

\section{References}

ADELSTein, F. E., and SChmidt, w. (1968) Arch. Soc. oftal. hisp.-amer., 28, 752

BEDFORD, P. D., and DANIEL, P. M. (1960) Amer. F. Ophthal., 49, 723

DUKE-ELDER, s. (1952) “Textbook of Ophthalmology", vol. 5, p. 56r6. Kimpton, London HORNER, F. (1864) Klin. Mbl. Augenheilk., 2, 186

REESE, A. B. (1963) "Tumors of the Eye", 2nd ed., p. 525. Harper and Row, New York, Evanston. and London

willis, R. A. (1952) "The Spread of Turnours in the Human Body", p. 284. Butterworth, London - (1953) "Pathology of Tumours", 2nd ed., p. 179. Butterworth, London

Wintersteiner, H. (1899) Klin. Mbl. Augenheilk., 37, 33 I 